\title{
Measured Laboratory and In-Use Fuel Economy Observed over Targeted Drive Cycles for Comparable Hybrid and Conventional Package Delivery Vehicles
}

\author{
Michael P. Lammert, Kevin Walkowicz, Adam Duran and Petr Sindler \\ National Renewable Energy Laboratory
}

\begin{abstract}
This research project compares the in-use and laboratoryderived fuel economy of a medium-duty hybrid electric drivetrain with "engine off at idle" capability to a conventional drivetrain in a typical commercial package delivery application. Vehicles in this study included eleven model year 2010 Freightliner P100H hybrids that were placed in service at a United Parcel Service (UPS) facility in Minneapolis, Minn., during the first half of 2010. These hybrid vehicles were evaluated for 18 months against eleven model year 2010 Freightliner P100D diesels that were placed in service at the same facility a couple months after the hybrids. Both vehicle study groups use the same model year 2009 Cummins ISB 200 HP engine. The vehicles of interest were chosen by comparing the average daily mileage of the hybrid group to that of a similar size and usage diesel group. The driving characteristics of the two study groups were examined in detail by collecting and analyzing two periods of Global Positioning System and controller area network (CAN) bus data. The results of this drive cycle study indicated a need to have the two investigated groups switch route assignments mid-study because of significantly different driving patterns, which UPS accommodated, to facilitate an accurate comparison.
\end{abstract}

The in-use fuel economy was evaluated using UPS's fueling and mileage records, periodic electronic control module image downloads, and J1939 CAN bus recordings during the two periods of duty cycle study. The drive cycle analysis was used to select three standardized laboratory drive cycles that would encompass the range of real world in-use data. The NYC Composite cycle, the HTUF Class 4 cycle, and the CARB HHDDT cycle were tested at the National Renewable
Energy Laboratory's Renewable Fuels and Lubricants Laboratory. The hybrid vehicle demonstrated $39 \%, 45 \%$, and $21 \%$ improvement in ton-mi./gal fuel economy on these test cycles, respectively. Analysis of the in-use fuel economy ranged from $13 \%$ to $29 \%$ hybrid advantage depending on measurement method and the associated delivery route assignment switch analysis showed $13 \%$ to $26 \%$ hybrid advantage on the less kinetically intense original diesel route assignments and $20 \%$ to $33 \%$ hybrid advantage on the more kinetically intense original hybrid route assignments.

\section{INTRODUCTION}

Parallel hybrid drivetrains are an important petroleum reduction strategy for fleets to employ. These drivetrains consist of a traction battery and an electric motor integrated into a traditional powertrain. These systems offer the potential to save fuel by limiting the transient operation of the engine and by recapturing energy as the vehicle slows down through regenerative braking.

Because hybrid technology is still relatively new, particularly to the medium duty vehicle segment, and because fuel savings from hybrids are highly dependent on the duty cycle they are driven on, there are still questions to be answered about when and where this technology offers a valuable return on investment in the form of fuel savings.

The objective of this project was to evaluate the actual fuel economy under a range of well-documented duty cycles in the field and in the laboratory. 


\section{BACKGROUND AND METHODS}

United Parcel Service (UPS) placed eleven new hybrids into service in Minneapolis in April 2010 as part of a purchase of 200 new hybrid step delivery vans. Driver training on hybrid operation was implemented at the same time. Conventional vans of the same model were placed in service in Minneapolis from April thru June 2010. The National Renewable Energy Laboratory (NREL) evaluated the first generation of these UPS/Eaton hybrids in Phoenix, Ariz., from January 2008 thru December 2010 [1,2]. The secondgeneration hybrids studied in Minneapolis include an "engine off at idle" function and meet 2007 emissions standards, among other improvements that warranted further study of this evolving technology.

\section{Vehicle Selection and Details}

All eleven hybrid P100 vehicles in service in Minneapolis were included in the study. Eleven vehicles from the more extensive conventional fleet of new P100s were chosen to be included in the study by comparing UPS route data from the routes the new hybrids and conventional vehicles were being assigned to. These route data were collected by UPS from older vehicles assigned to these routes. Conventional vehicles were chosen from available route assignments that matched most closely to the statistics available for the hybrid route assignments. However, the hybrids had been assigned to the most dense, lower average speed, and higher stops per mile routes, and it was suspected that a route mismatch would be inevitable and would require a mid-study route switch between the study groups. Table 1 lists the vehicles' specifications, and Table 2 lists pertinent hybrid system details.

Table 1. Study Van Details.

\begin{tabular}{|l|l|l|}
\hline Van Specification & $\begin{array}{l}\text { Conventional } \\
\text { Vans }\end{array}$ & $\begin{array}{l}\text { Hybrid } \\
\text { Electric Vans }\end{array}$ \\
\hline Van manufacturer & Freightliner & Freightliner \\
\hline Van model & P100D & P100H \\
\hline Van model year & 2010 & 2010 \\
\hline Engine manufacturer & Cummins & Cummins \\
\hline Engine model & ISB 200 HP & ISB 200 HP \\
\hline Engine model year & 2009 & 2009 \\
\hline Emissions equipment & DPF & DPF \\
\hline Transmission & $\begin{array}{l}\text { Allison } \\
\text { Automatic }\end{array}$ & Eaton Hybrid \\
\hline $\begin{array}{l}\text { Retarder/regenerative } \\
\text { braking }\end{array}$ & None & $\begin{array}{l}\text { Regenerative } \\
\text { Braking }\end{array}$ \\
\hline Air conditioning type & None & None \\
\hline $\begin{array}{l}\text { Gross vehicle weight } \\
\text { rating }\end{array}$ & $23,000 \mathrm{lbs}$ & $23,000 \mathrm{lbs}$ \\
\hline
\end{tabular}

Table 2. Hybrid System Details.

\begin{tabular}{|l|l|}
\hline Category & Hybrid System Description \\
\hline Manufacturer/integrator & Eaton Corporation \\
\hline Transmission & $\begin{array}{l}\text { Fuller medium-duty automated } \\
6 \text {-speed manual }\end{array}$ \\
\hline Electric Motor & $\begin{array}{l}\text { Synchronous brushless with } \\
\text { permanent magnet }\end{array}$ \\
\cline { 2 - 2 } & $26 \mathrm{~kW}$ continuous power \\
\cline { 2 - 2 } & $44 \mathrm{~kW}$ peak power \\
\hline Energy storage & Lithium ion batteries \\
\cline { 2 - 2 } & $340 \mathrm{VDC}$ \\
\cline { 2 - 2 } & $1.8 \mathrm{kWh}$ total storage \\
\hline
\end{tabular}

\section{Duty-Cycle Analysis and Test Cycle Selection}

\section{GPS and J1939 Vehicle Data Logging}

Isaac Instruments DRU900/908 data logging devices with 5 $\mathrm{Hz}$ Global Positioning System (GPS) antennas and J1939 CAN bus connections were deployed to the UPS fleet on two occasions. The first was from July 14, 2010, to July 29, 2010, and the second was from April 12, 2011, to June 21, 2011. On the first occasion only three Isaacs were available (other GPS-only devices were also deployed but are not included in this report), and on the second occasion seven vans from each group were instrumented with the devices for most of the duration. In total, 338 vehicle days of hybrid operation and 252 vehicle days of conventional operation on eight vans from each group were documented. The GPS and J1939 channels were recording at a $5-\mathrm{Hz}$ rate. J1939 CAN bus channels included wheel-based vehicle speed, engine speed, and engine fuel rate among others (see Appendix Table A1 for a complete list). These same devices and channel settings (minus GPS) were used during laboratory dynamometer testing to capture vehicle systems activity during the test runs.

\section{DRIVETM Analysis}

Filtration and analysis of the in-use field data collected as part of the study were performed using NREL's Drive-Cycle Rapid Investigation, Visualization, and Evaluation (DRIVETM) analysis tool [푸뇨. Employing NREL's DRIVE analysis tool, researchers were able to ensure data quality by analyzing daily vehicle operation via a list of approximately 150 unique drive cycle metrics. The 150 drive cycle metrics calculated as part of the analysis ranged from high level route descriptors such as average driving speed $(\mathrm{mph})$ and stops per mile, down to vehicle energy level metrics such as kinetic power density consumed $(\mathrm{W} / \mathrm{kg}$ ) and kinetic intensity, all of which were calculated using different variations of the fundamental road load equation [ $[5]$. When performing the road load calculations, it was assumed, due to a lack of 
reliable elevation data, that the vehicle differential elevation component was negligible as were the effects of road grade.

\section{Lab Test Cycle Selection}

When selecting standard test cycles for lab testing purposes, a multivariate least squares method was employed in an effort to select standard cycles most reflective of the aggregate group in-use data. By performing a comparison of drive cycle metrics such as average driving speed, stops per mile, and others, a highly representative set of test cycles was chosen representing driving conditions displaying the least, average, and greatest hybrid advantage. The corresponding cycles chosen in order of least to greatest advantage were the California Air Resources Board Heavy Heavy-Duty Diesel Truck (HHDDT), HTUF4, and New York City (NYC) Comp.

\section{Laboratory Chassis Dynamometer Testing Procedures}

When tested, the vehicle is secured to the dynamometer with the drive axle(s) over the rollers. The vehicle is exercised by a driver following a prescribed speed trace on the test aid monitor. A large fan is typically used to force cooling air onto the vehicle radiator to roughly simulate the ram cooling effect of a vehicle in motion. The engine exhaust stream is collected by the emissions measurement system for analysis, and various vehicle parameters are monitored and logged by the data acquisition system.

To assure the accuracy and consistency of road load simulation, the dynamometer is subjected to various procedures and checks. From a practical perspective, the daily testing routine consists of the following steps. In the morning, the vehicle is lifted off the rollers and the dynamometer is subjected to its warm-up procedure until the parasitic losses stabilize. Then the unloaded coastdown procedure is used to verify that the parasitic losses did not change from the previous testing due to component failure and that the load cell calibration has not drifted. Following this verification, the vehicle is dropped on the rollers and driven for roughly 20 minutes to warm up. After the warmup, a conditioning test run is performed to stabilize the vehicle's temperature for a given test cycle. At this point, the system is ready to either set or verify the correct road load simulation through a loaded coastdown procedure. The following test runs are considered usable in terms of data validity provided the road load simulation proves consistent. This is verified after each test to ensure that changing conditions (test facility temperature) are not affecting vehicle loading. To maximize consistency, the soak period between one test end and the following test start is kept at 20 minutes.

\section{Emissions Measurement}

The emissions measurement system is based on the recommendations in Code of Federal Regulations Section 40, Part 86, Subpart N. The system consists of a full flow dilution tunnel with a constant volume sampling system for mass flow measurement. The tunnel flow rate is measured and controlled using critical flow venturis. The dilution and engine combustion air is supplied by an air handling unit that maintains the desired air temperature and humidity.

The diluted engine exhaust was sampled for gravimetric particulate matter analysis and by a Horiba MEXA 7100 series system for gaseous analysis, including total hydrocarbons, oxides of nitrogen, carbon monoxide (CO), and carbon dioxide. The gas analytical system was verified prior to beginning the testing period, including linearization checks and oxides of nitrogen efficiency test. On a daily basis, the analyzers were zero and span calibrated, and each test was bracketed by zero and span response readings used for corrections. The emissions measurement data were then reduced to distance specific mass results using the Code of Federal Regulations-recommended calculations, including humidity, dry to wet, zero, span, and background corrections.

\section{Fuel Consumption Measurement}

The fuel consumption measurement in this project relied primarily on a gravimetric approach. The engine fuel supply and return lines were connected to a fuel container placed on a scale. The scale mass measurements were recorded in a real time along with all the test data. The difference between the beginning and the end test mass measurement indicated the mass of fuel consumed during the test. Prior to testing, the scale calibration was verified with a known calibration weight. A Sartorius Midrics MAPP1U-60ED-L was used for this test. The fuel consumption measurement was also backed up using the carbon balance method back-calculating the mass of fuel consumed from measurement of exhaust emission constituents.

\section{$\underline{\text { State-of-Charge Considerations }}$}

SAE Recommended Practice J2711 is a recommended protocol for measuring fuel economy and emissions of hybrid-electric and conventional heavy-duty vehicles and was used for this project. The recommended practice describes a state-of-charge correction for charge-sustaining hybrid electric vehicles. All the tests in this program involving the hybrid electric vehicle resulted in negligible net energy changes and thus did not require correction as per SAE J2711.

\section{In-Use Vehicle Fueling Records Collection and Statistical Analysis}

UPS provided electronic records of daily mileage and fueling event records for analysis for each vehicle studied in the field. Monthly fuel economy results were tabulated from these records for each van. Due to inconsistencies in fueling records that resulted in some unattainable monthly fuel economy results, a statistical method known as Chauvenet's 
Criterion [4] was used to identify van-monthly mile-pergallon (mpg) results that were statistical outliers.

\section{Fueling Record Outlier Analysis via Chauvenet's Criterion}

Chauvenet's Criterion was applied to the data set to identify individual monthly mpg outliers within the overall group of fueling records. Chauvenet's Criterion is an iterative statistical method applied to data sets that either accepts or rejects individual statistical outliers found in experimental data based on the data set size, mean, and standard deviation [6]. As part of employing Chauvenet's Criterion, the probability of the largest outlier in the data set is determined using the data set mean and standard deviation. If the probability of the observed outlier multiplied by the size of the data set results in a value less than 0.5 , it is concluded that the statistical outlier observed as part of the data set can be rejected based on the limited probability of this outlier occurring as part of the data set. If the outlier is rejected, the data set mean and standard deviation are recalculated excluding the rejected data point as part of the data set, and the probability for the next largest remaining outlier is determined. This process is repeated until no further outliers are found to be rejected. From the 198 vehicle-months of recorded fuel economy data on each vehicle group, this method removed 22 vehicle-months from the diesel van group and 48 vehicle months from the hybrid van group (seven had the value of divided by zero gallons of fuel) that were statistically impossible based on the characteristics of the 13-month first route assignment data set and the 5-month switched route assignment data set. In addition to employing Chauvenet's Criterion to remove statistically impossible data points, an additional $95 \%$ confidence interval analysis was performed on the remaining outliers not rejected via the Chauvenet's Criterion approach to remove an additional four vehicle-months from the diesel group. The $95 \%$ confidence interval was chosen to ensure that the data analyzed as part of the study reflected typical vehicle behavior and would not be influenced by the effect of low-probability events. A visual inspection of the data upon the conclusion of this process revealed that most of the data points removed by this approach were obvious data artifacts impossible for individual vehicles to attain (see Appendix Table A2). However, by employing a consistent statistical approach to the entire fueling data set, the grey areas for each vehicle were treated in the same manner and either accepted or rejected, resulting in a realistic and consistent data set. Additionally, one hybrid van had to be removed from fueling records analysis for the duration of the first route assignment because the driver consistently did not report fueling events.

\section{RESULTS}

\section{Delivery Van in Use Duty Cycle Results}

Comparing the routes driven by the two vehicle groups is difficult because of the disparity in the average daily miles driven. The conventional vans averaged 64 miles a day while the hybrids averaged only 43 miles a day due to their route assignments. Figure 1 shows the average distance (as a percentage) that vans with GPS loggers drove at different vehicle speeds. The hybrids drove a greater percentage of their distance at slower speeds than the diesels did, and the diesels drove more of their miles operating at higher speeds.

- The hybrid vans drove $44 \%$ of their miles below $20 \mathrm{mph}$, while the conventional vans drove only $30.5 \%$ of their miles at those slow speeds.

- Both van groups drove a similar percentage of their miles at the intermediate speeds of $20-50 \mathrm{mph}: 47 \%$ for conventional vans and $43 \%$ for hybrid vans.

- The hybrid vans drove only $13 \%$ of their miles above 50 mph, while the conventional vans drove $22 \%$ of their miles at those highway speeds.

The greater percent of miles driven by the hybrids at slower speeds is an indication of a more urban duty cycle. The lower percentage of miles driven at highway speeds is an indication of routes closer to the depot.

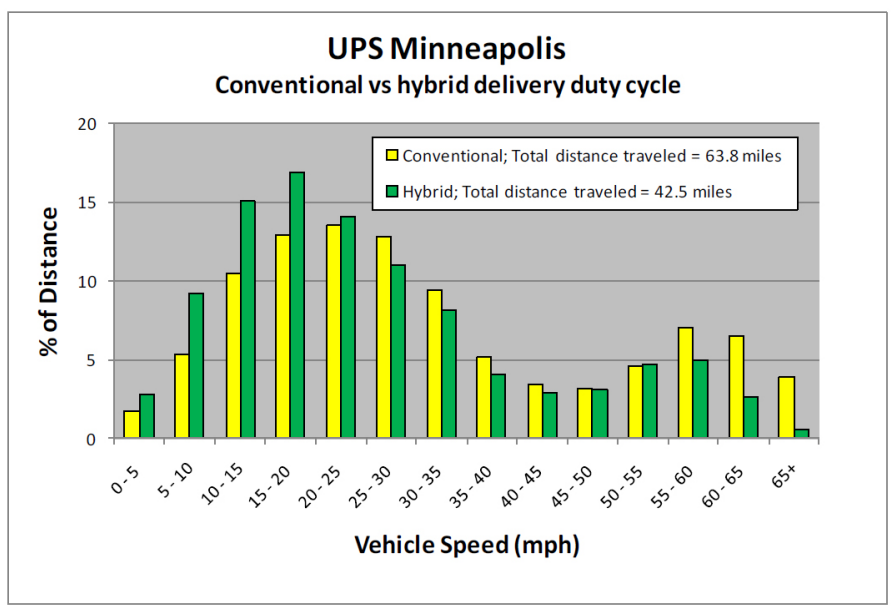

Figure 1. Hybrid and diesel duty cycle breakdown by miles (\%)

Figure 2 shows the average distance (in miles) that vans with GPS loggers drove at different vehicle speeds. This distancebased chart highlights a different breakdown of the routes.

- The conventional vans drove more miles at all speeds above $10 \mathrm{mph}$.

- The hybrid and conventional vans both drove 17 miles in the $0-20$ mph range. 
- The hybrid vans drove $37 \%$ fewer miles in the $20-50 \mathrm{mph}$ range: 19 vs. 30 . This indicates the conventional vans had longer surface street drives between delivery stops.

- The hybrid vans drove $62 \%$ fewer miles in the $50+\mathrm{mph}$ highway range: 6 vs. 15. This indicates the conventional vans had longer highway sections to get to their assigned delivery areas.

These figures and statistics also show a very clear picture of a bi-modal duty cycle. We can separate out the "leg" or highway section from the depot to the delivery area from the delivery routes zone itself. The conventional vans were on routes with a longer leg portion, which leaves less time to be in the delivery zone. They also tended to have less dense delivery zones. The hybrids, on the other hand, had a shorter leg from the depot to the delivery zone and had a denser delivery zone, resulting in a high percentage of low-speed, slow mile accumulation driving.

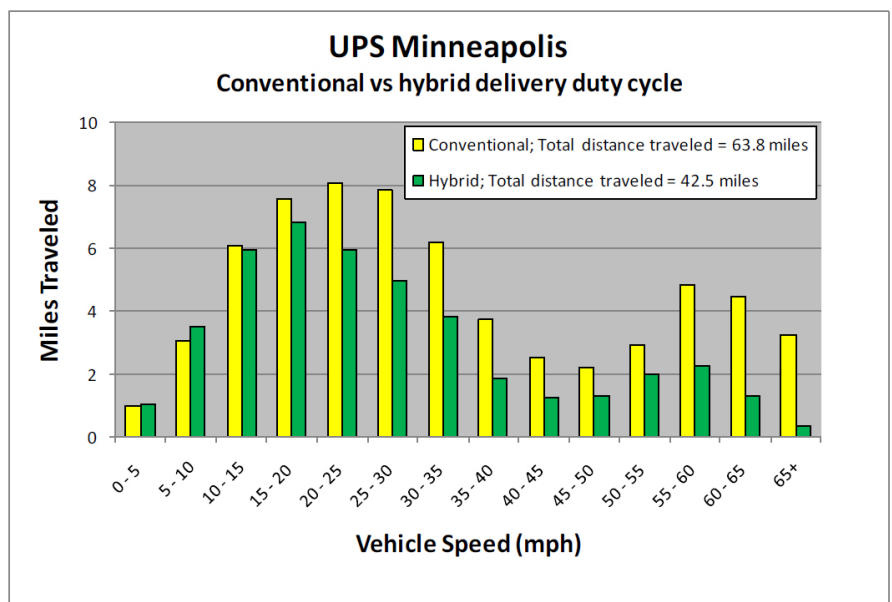

Figure 2. Hybrid and diesel duty cycle breakdown by miles traveled

Table 3 presents other duty-cycle statistics gathered from the GPS data logging, which may be summarized as follows.

- The hybrids' average driving speed of $16.5 \mathrm{mph}$ was $21 \%$ lower than the conventional vans' $20.7 \mathrm{mph}$.

- The hybrids averaged roughly the same number of stops per day as the conventional vans' (205 vs. 220 for the diesels).

- The hybrids had 5.3 stops per mile, $37 \%$ more than the conventional vans' 3.9 .

- The hybrids had 25.7 acceleration events per mile, $34 \%$ more than the conventional vans' 19.2.
These statistics indicate that the hybrids were operating on very different routes than the diesels. Because of these major differences, the study groups switched routes in the summer of 2011 (June - August). As of August 2011 the hybrid vans had assumed the drive characteristics of the conventional group and the conventional vans had assumed the drive characteristics of the hybrid group. The results of the route switch are discussed below. Hybrid fuel economy advantage is compared for the groups on the same routes as well as over the full study period.

\section{Delivery Van Fuel Economy}

\section{Laboratory Testing Gravimetric and J1939 Reported Fueling Comparison}

All laboratory fuel economy results are averaged from four test runs of each cycle. Gravimetric fuel economy results for the vans are shown in Table 4. The hybrid vans showed a $13 \%-36 \%$ improvement in fuel economy over the conventional vans on the tested duty cycles.

Fuel economy results from recording of the J1939 reported fuel rate for the vans are shown in Table 5. The hybrid vans showed a $16 \%-43 \%$ improvement in fuel economy over the conventional vans on the tested duty cycles using this method.

Data logger measured and calculated fuel economies were consistently $6 \%$ better on the conventional van and $11 \%$ better on the hybrid van as compared to the laboratory gravimetric measurements of those test runs. It is supposed that J1939 fuel rate reporting is not at a high enough resolution to accurately calculate fuel economy in-use because the error was solely in fuel consumed, not in miles traveled during the test. However, the run by run repeatability of the offset percentage was such that a correction factor can be applied to achieve more accurate in-field analysis with data logging of this channel. Applying $6 \%$ and $11 \%$ reductions, respectively, to each laboratory test run resulted in much more acceptable error values (less than 2\%); therefore, this adjustment is applied later to the in-field data collected by the same data logging device, J1939 channel and analysis method to better represent the real-world data. Table $\underline{6}$ shows the J1939 fuel economy results using this correction of individual test runs.

Ton fuel economy results (based on gravimetric fuel consumption measurement and tested vehicle weight) for the vans are shown in Table 7. The hybrid vans showed a $21 \%-45 \%$ improvement in fuel economy over the conventional vans on the tested duty cycles. 
Table 3. Drive Cycle Statistics from Vans with GPS Loggers from Each Study Group

\begin{tabular}{|l|c|c|c|c|}
\hline $\begin{array}{l}\text { Cycle Statistics } \\
\text { Distance traveled } \\
\text { (miles) }\end{array}$ & Diesel Average & Hybrid Average & $\begin{array}{c}\text { Difference } \\
\text { (Diesel - Hybrid) }\end{array}$ & \% Difference \\
\hline $\begin{array}{l}\text { Average speed over } \\
\text { cycle (mph) }\end{array}$ & 11.8 & 42.5 & 21.3 & $-33 \%$ \\
\hline $\begin{array}{l}\text { Average driving speed } \\
\text { (mph) }\end{array}$ & 20.7 & 8.3 & 3.5 & $-30 \%$ \\
\hline Maximum speed (mph) & 66.2 & 16.5 & 4.3 & $-21 \%$ \\
\hline Time at zero speed (s) & 8670.0 & 60.5 & 5.7 & $-9 \%$ \\
\hline $\begin{array}{l}\text { Acceleration (\% of total } \\
\text { cycle) }\end{array}$ & 29.5 & 26.6 & --- & -- \\
\hline $\begin{array}{l}\text { Deceleration (\% of total } \\
\text { cycle) }\end{array}$ & 27.6 & 23.9 & 2.9 & $-10 \%$ \\
\hline $\begin{array}{l}\text { Average acceleration } \\
\text { (ft/s }{ }^{2}\end{array}$ & 2.2 & 1.9 & 3.7 & $-13 \%$ \\
\hline $\begin{array}{l}\text { Average deceleration } \\
\text { (ft/s }{ }^{2} \text { ) }\end{array}$ & -2.3 & -2.1 & -1.3 & $-14 \%$ \\
\hline $\begin{array}{l}\text { Number of acceleration } \\
\text { events }\end{array}$ & 1157.5 & 1015.9 & -0.2 & $-8 \%$ \\
\hline $\begin{array}{l}\text { Number of acceleration } \\
\text { events per mile }\end{array}$ & 19.2 & 25.7 & 141.7 & $-12 \%$ \\
\hline $\begin{array}{l}\text { Number of deceleration } \\
\text { events }\end{array}$ & 1157.5 & 1015.9 & -6.5 & $34 \%$ \\
\hline $\begin{array}{l}\text { Number of deceleration } \\
\text { events per mile }\end{array}$ & 19.2 & 25.7 & 141.7 & $-12 \%$ \\
\hline Number of stops & 219.9 & 205.1 & -6.5 & $34 \%$ \\
\hline $\begin{array}{l}\text { Number of stops per } \\
\text { mile }\end{array}$ & 3.9 & 5.3 & 14.8 & $-7 \%$ \\
\hline
\end{tabular}

Table 4. Fuel Economy (gravimetric) of Hybrid and Diesel Van on Various Cycles on Chassis Dynamometer.

\begin{tabular}{|l|c|c|c|}
\hline \multicolumn{1}{|c|}{$\begin{array}{c}\text { Gravimetric Fuel } \\
\text { Economy }\end{array}$} & $\begin{array}{c}\text { NYC } \\
\text { Comp }\end{array}$ & HTUF4 & HHDDT \\
\hline Conventional P100D & 6.8 & 7.5 & 9.6 \\
\hline Hybrid P100H (mpg) & 8.8 & 10.2 & 10.9 \\
\hline Hybrid Advantage & $29 \%$ & $36 \%$ & $13 \%$ \\
\hline T test P Value & 0.0001 & 0.0000 & 0.0002 \\
\hline
\end{tabular}

Table 5. Fuel Economy from J1939 data logger of Hybrid and Diesel Van on Various Cycles on Chassis Dynamometer.

\begin{tabular}{|l|c|c|c|}
\hline \multicolumn{1}{|c|}{ J1939 Fuel Economy } & $\begin{array}{c}\text { NYC } \\
\text { Comp }\end{array}$ & HTUF4 & HHDDT \\
\hline Conventional P100D & 7.2 & 7.9 & 10.3 \\
\hline Hybrid P100H (mpg) & 9.9 & 11.3 & 12.0 \\
\hline Hybrid Advantage & $37 \%$ & $43 \%$ & $16 \%$ \\
\hline
\end{tabular}


Table 6. Corrected Fuel Economy from J1939 Data Loggers of Hybrid and Diesel Vans on Various Cycles on Chassis Dynamometer.

\begin{tabular}{|l|c|c|c|}
\hline $\begin{array}{c}\text { Corrected J1939 Fuel } \\
\text { Economy }\end{array}$ & $\begin{array}{c}\text { NYC } \\
\text { Comp }\end{array}$ & HTUF4 & HHDDT \\
\hline Conventional P100D (mpg) & 6.8 & 7.4 & 9.7 \\
\hline Hybrid P100H (mpg) & 8.8 & 10.0 & 10.7 \\
\hline Hybrid Advantage & $30 \%$ & $36 \%$ & $10 \%$ \\
\hline
\end{tabular}

Table 7. Ton Fuel Economy (gravimetric) of Hybrid and Diesel Van on Various Cycles on Chassis Dynamometer.

\begin{tabular}{|l|c|c|c|}
\hline $\begin{array}{c}\text { Gravimetric Ton Fuel } \\
\text { Economy }\end{array}$ & $\begin{array}{c}\text { NYC } \\
\text { Comp }\end{array}$ & HTUF4 & HHDDT \\
\hline $\begin{array}{l}\text { Conventional P100D } \\
\text { (ton-mi./gal) }\end{array}$ & 51.1 & 56.2 & 72.0 \\
\hline $\begin{array}{l}\text { Hybrid P100H (ton- } \\
\text { mi./gal) }\end{array}$ & 70.9 & 81.6 & 87.2 \\
\hline Hybrid Advantage & $39 \%$ & $45 \%$ & $21 \%$ \\
\hline T test P Value & 0.0000 & 0.0000 & 0.0001 \\
\hline
\end{tabular}

\section{UPS Fueling and Mileage Records Analysis}

Using the Chauvenet's Criterion and $95 \%$ confidence interval analysis described above, 26 diesel-group vehicle months of fuel economy data and 48 hybrid-group vehicle months of fuel economy data were removed from the total of 198 vehicle months of fuel economy results presented in this report. The resulting fuel economy comparison results are shown in Table 8. The lower than expected 13\% improvement is driven primarily by the route assignment mismatch; for about 13 of the 18 months the conventional group was on a higher speed duty cycle, accumulating many more miles at a higher mpg than they would have had they been on the same routes as the hybrids.

Table 8. Fuel Economy (in-use records) of Hybrid and Diesel Vans.

\begin{tabular}{|l|l|l|l|}
\hline $\begin{array}{l}\text { Fuel Economy from In- } \\
\text { Use Records }\end{array}$ & $\begin{array}{l}\text { Mileage } \\
\text { Total }\end{array}$ & $\begin{array}{l}\text { Fuel } \\
\text { Used }\end{array}$ & MPG \\
\hline Conventional P100D & 218,225 & 24,673 & 8.8 \\
\hline Hybrid P100H Group & 145,568 & 14,615 & 10.0 \\
\hline Percent Difference & $-33 \%$ & $-41 \%$ & $13 \%$ \\
\hline $\begin{array}{l}\text { T test P Value } \\
\text { (cumulative mpg of } \\
\text { individual vans in the } \\
\text { group) }\end{array}$ & & 0.0035 \\
\hline
\end{tabular}

Because the duty cycle analysis revealed that the study groups were operating on significantly different duty cycles, a group route switch was arranged with UPS so that all hybrid vehicles took on a route previously operated by a conventional study group van and the conventional study group vans were assigned to the hybrid routes. This enabled a comparison of the study groups on the same routes, but during different time periods. The whole 18 months is not represented, rather the same 5-month calendar period is compared to eliminate any seasonal variation in weather and loads. Table 9 shows the fuel economy of the study groups on the original conventional group routes and the original hybrid group routes. "Conventional Route 1" indicates the original routes the conventional vans were assigned to and the hybrids took over after the route switch. "Conventional Route 2" indicates the original routes the hybrids were assigned to and the conventional vans took over after the route switch. Both study groups had higher mpg on Conventional Route 1 than on Conventional Route 2, which validates the statistical analysis indicating that the conventional group was on a somewhat less demanding duty cycle while the hybrids were on a harder one. Also of note is that the hybrid advantage was $13 \%$ on the less kinetically intense, more highway biased route assignments, matching well to the laboratory results on the HHDDT cycle while they achieved $20 \%$ hybrid advantage on the more kinetically intense Conventional Route 2 assignments (although the second route comparison was not quite statistically significant because of removed fueling months eliminating some vans, which reduced the sample set).

Table 9. Route Switch Fuel Economy (in-use records) of Hybrid and Diesel Van on two route sets.

\begin{tabular}{|l|l|l|}
\hline & $\begin{array}{l}\text { Conventional } \\
\text { Route Set 1 }\end{array}$ & $\begin{array}{l}\text { Conventional } \\
\text { Route Set 2 }\end{array}$ \\
\hline Conventional & Aug - Dec 2010 & Aug - Dec 2011 \\
\hline Mileage & 75,404 & 37,901 \\
\hline Fuel & 8,233 & 4,822 \\
\hline Group MPG & 9.2 & 7.9 \\
\hline Hybrid & Aug - Dec 2011 & Aug - Dec 2010 \\
\hline Mileage & 62,991 & 32,149 \\
\hline Fuel & 6,086 & 3,417 \\
\hline Group MPG & 10.4 & 9.4 \\
\hline Hybrid Advantage & \multicolumn{1}{|c|}{$\mathbf{2 0 \%}$} & \\
\hline $\begin{array}{l}\text { T test P Value } \\
\text { (cumulative mpg of } \\
\text { individual vans in } \\
\text { the group) }\end{array}$ & \multicolumn{1}{|c|}{0.0015} & 0.1468 \\
\hline
\end{tabular}




\section{Periodic ECM Image Download Analysis}

ECM "image snapshots" were collected from each van nine times between December 7, 2010, and January 18, 2012. These images report numerous counters within the ECM, including how many miles have been driven and how much fuel has been consumed as well as breaking down those values into categories (idle fuel, top gear fuel, fuel used for DPF regenerations, top gear miles, etc.). By comparing these images with those taken previously, it is possible to calculate fuel economy over a given period of time for each van. The accuracy of these ECM fueling records over time has not been evaluated, and it is not known if the inaccuracy demonstrated during the J1939 CAN bus recording of the laboratory test was due to reporting frequency or ECM accuracy. As such, the correction factors discussed above have not been applied to these results. Table 10 shows the miles driven, gallons consumed, and fuel economy for each of the study vehicles. The hybrid group demonstrated $29 \%$ better fuel economy than the conventional group over the whole time covered by these image comparisons, which includes both route assignments in a nearly equal time split, although seasonal differences are not balanced due to the later start of ECM image downloading as compared to the beginning of the study.

Table 10. Fuel Economy (ECM records) of Hybrid and Diesel Vans.

\begin{tabular}{|l|l|l|l|}
\hline $\begin{array}{c}\text { Fuel Economy from in- } \\
\text { Use Records }\end{array}$ & $\begin{array}{l}\text { Mileage } \\
\text { Total }\end{array}$ & $\begin{array}{l}\text { Fuel } \\
\text { Used }\end{array}$ & MPG \\
\hline $\begin{array}{l}\text { Conventional P100D } \\
\text { Group }\end{array}$ & 166,064 & 19,139 & 8.7 \\
\hline Hybrid P100H Group & 148,986 & 13,301 & 11.2 \\
\hline Percent Difference & $-10 \%$ & $-31 \%$ & $29 \%$ \\
\hline $\begin{array}{l}\text { T test P Value } \\
\text { (cumulative mpg of } \\
\text { individual vans in the } \\
\text { group) }\end{array}$ & & 0.0001 \\
\hline
\end{tabular}

Periods before and after the route switch were also evaluated so the groups could again be compared on the same routes albeit at different time periods. Data on the original routes came from the period of December 7, 2010, to June 24, 2011, and the second route data are from the period of August 16, 2011, until January 18, 2012. Table 11 shows the group fuel economy results for each group on each route assignment. The same trends seen in the fueling records analysis of the route switch are seen in the ECM data. Both study groups had higher mpg on Conventional Route 1 than Conventional Route 2, and the hybrid advantage was greater on Conventional Route 2 than Conventional Route 1. The hybrid group demonstrated $26 \%$ better fuel economy on the original conventional routes and $33 \%$ better fuel economy on the more kinetically intense original hybrid routes.
Table 11. Fuel Economy (ECM Records) of Hybrid and Diesel Vans.

\begin{tabular}{|l|l|l|}
\hline & $\begin{array}{c}\text { Conventional } \\
\text { Route Set 1 }\end{array}$ & $\begin{array}{c}\text { Conventional } \\
\text { Route Set 2 }\end{array}$ \\
\hline Conventional & Dec '10 - June & Aug '11 - Jan '12 \\
\hline Mileage & 99,877 & 45,896 \\
\hline Fuel (gal) & 11,146 & 5,706 \\
\hline Group MPG & 9.0 & 8.0 \\
\hline Hybrid & Aug '11 - Jan & Dec '10 - June'11 \\
\hline Mileage & 64,308 & 61,930 \\
\hline Fuel (gal) & 5,691 & 5,808 \\
\hline Group MPG & 11.3 & 10.7 \\
\hline Hybrid Advantage & $\mathbf{2 6 \%}$ & $\mathbf{3 3 \%}$ \\
\hline $\begin{array}{l}\text { T test P Value } \\
\text { (cumulative mpg of } \\
\text { individual vans in } \\
\text { the group) }\end{array}$ & 0.0003 & \multicolumn{1}{|c|}{0.0001} \\
\hline
\end{tabular}

\section{GPS/J1939 Duty Cycle Study Daily Fuel Economy}

The same Isaac data logging device used during the laboratory testing was used during two periods to capture inuse fleet fuel economy. Seven vans from each study group were instrumented for most of the second period. In total, 338 days of hybrid operation and 252 days of conventional operation were documented. The fuel economy calculations from these in-use days of J1939 and GPS recording are assumed to be affected by the same offsets seen in the laboratory tests and as such these data have been corrected using the factors discussed above. Table 12 shows the miles driven, fuel consumed, and average fuel economy from the study vehicles during this time.

\section{Table 12. Fuel Economy (Data Logging W/Correction Factor) of Hybrid and Diesel Vans.}

\begin{tabular}{|l|l|l|l|l|}
\hline $\begin{array}{c}\text { Fuel Economy } \\
\text { from GPS \& } \\
\text { J1939 Data }\end{array}$ & $\begin{array}{l}\text { Mileage } \\
\text { Total }\end{array}$ & $\begin{array}{l}\text { Fuel } \\
\text { Used }\end{array}$ & MPG & $\begin{array}{l}\text { Corrected } \\
\text { MPG }\end{array}$ \\
\hline $\begin{array}{l}\text { Conventional } \\
\text { P100D Group }\end{array}$ & 15,118 & 2,012 & 7.5 & 7.1 \\
\hline Hybrid P100H & 16,577 & 1,645 & 10.1 & 9.0 \\
\hline Percent & $10 \%$ & $-18 \%$ & $34 \%$ & $27 \%$ \\
\hline $\begin{array}{l}\text { T test P Value } \\
\text { (cumulative } \\
\text { mpg of } \\
\text { individual van } \\
\text { days) }\end{array}$ & & 0.0021 & 0.0063 \\
\hline
\end{tabular}

However, because detailed driving behavior is also known for each in-use driving day, comparisons of fuel economy to kinetic intensity, average driven speed, and stops per mile are possible. Figure 3 shows individual days of operation, vehicle averages, and the laboratory dynamometer results presented 
earlier compared to the average driven speed of the drive cycle. Figure 4 shows the same data compared to kinetic intensity. There is clear indication that the laboratory results bracketed the in-use operation of the study groups and accurately represented the trends for the two vehicle groups, while the in-use daily data points clearly show the random effects of varying drivers, loads, traffic, and weather that are not captured in laboratory testing and that tend to reduce fuel economy as compared to laboratory results. Also of note is how the hybrid days of operation clump at the lower driven speeds and higher kinetic intensity while the conventional days of operation are spread more evenly across the range.

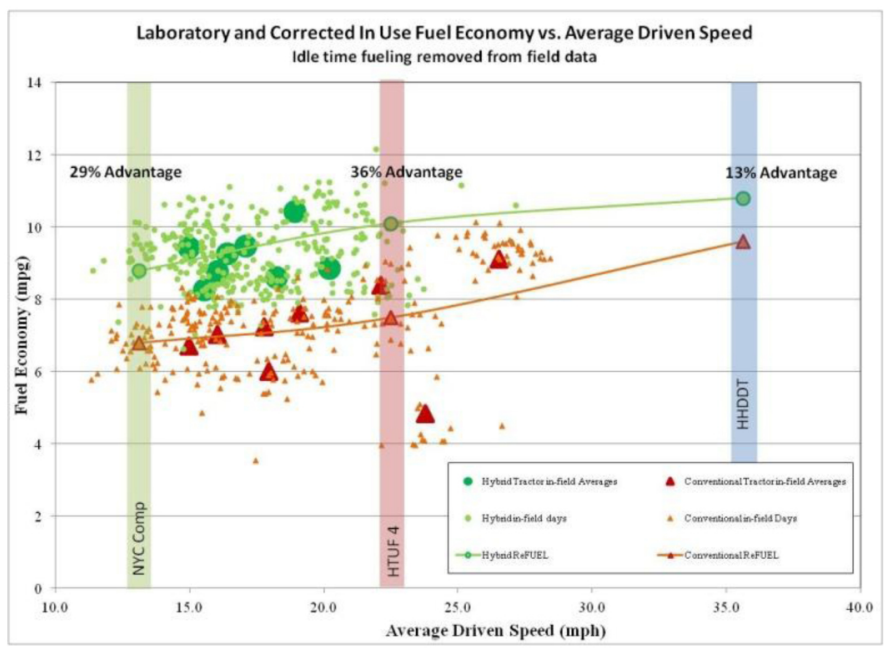

Figure 3. Laboratory and in-use fuel economy compared to average driven speed.

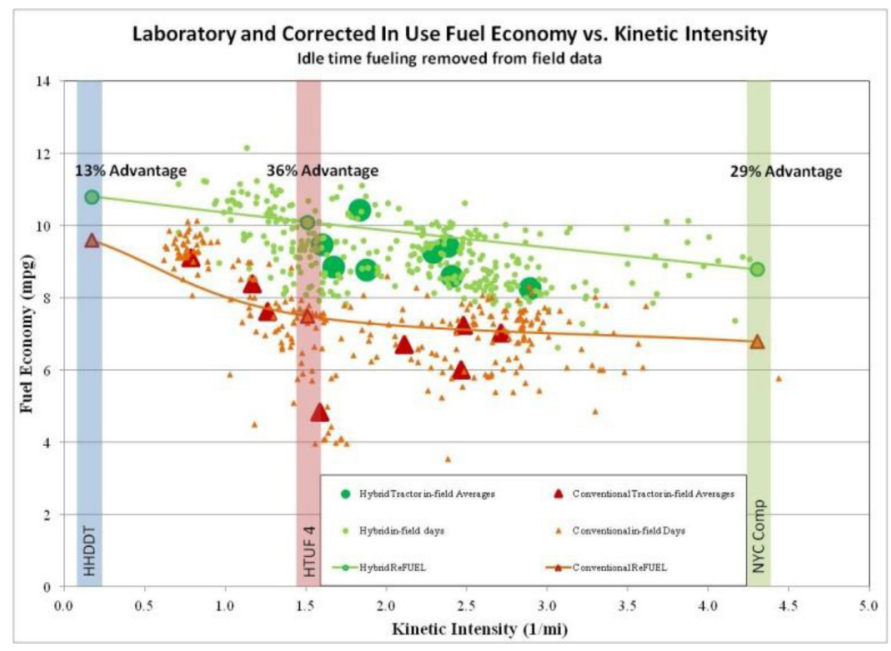

Figure 4. Laboratory and in-use fuel economy compared to kinetic intensity.

\section{Discussion}

The variety of fuel consumption measurement methods employed in this study all have their positive attributes and negative attributes. Laboratory dynamometer testing has definitive measurement of fuel consumed and miles traveled and shows what a vehicle is capable of under very specific circumstances. However, laboratory results are always going to miss some real in-use variables that can have significant effect on fuel economy such as idle time, changing load, weather, traffic conditions and driver aggressiveness. While some fleets utilize wireless recording of refueling events from vehicles, most, like this location, require drivers to take note of fueling events. This means the records are open to human error, which was demonstrated in the number of months that needed to be removed because of unattainable fuel economy numbers. The engine ECM keeps track of its commanded fueling and has the advantage of assigning that fuel to specific operations such as idle, cruise control, DPF regeneration etc. However, the error associated with these histories is unknown and likely to vary by engine model and possibly even within the engine RPM/load map of the engine. It also has the drawback of requiring periodic downloads from the study vehicles, which often are irregular because of logistics. Tabulating the engine fuel rate reported on the J1939 CAN bus takes any engine ECM error and adds error on top of that with possible issues of update rate and rounding/decimal clipping by the J1939. It has the advantage, though, of capturing true in-use conditions and all variability of those operations and through post processing fueling can be attributed to highway speeds, slower road speeds, and "idle" or zero vehicle speed operation. By utilizing this method both in the laboratory and in-use, a rough error correction can be calculated and applied. It should be noted that while the different methods varied somewhat in specific mpg numbers and in the resulting percent improvement from the hybrid drivetrain, all fuel economy measurement methods demonstrated very strong statistical significance through use of a t-test showing that the two study groups were indeed delivering different fuel economy results.

\section{SUMMARY/CONCLUSIONS}

By all methods of measure, the hybrids consistently are demonstrating a fuel economy advantage, vehicle by vehicle, month by month, day by day. Laboratory testing, long-term in-use analysis over a route switch, and daily calculated fueling all demonstrate a distinct relationship between duty cycle and the magnitude of demonstrated hybrid fuel economy advantage. The laboratory tests fully encompassed the range of fuel economy improvement found by the three in-use methods of measure of $13 \%$ to $36 \%$.

- Fueling records analysis seemed the most error-prone with roughly $20 \%$ of the data having to be statistically removed.

- Corrected GPS/J1939 and ECM analysis showed 26\%-33\% in-use fuel economy improvement.

- The majority of daily GPS route statistics placed most driving between the laboratory test cycles of NYC Comp and HTUF4, which showed $29 \%$ and $36 \%$ improvement, 
respectively, which matches well with the in-use data from J1939 and ECM images.

\section{REFERENCES}

1. Lammert, M., "Twelve-Month Evaluation of UPS Diesel Hybrid Electric Delivery Vans," NREL/TP-540-44134, December 2009.

2. Lammert, M. and Walkowicz, K., "Thirty-Six Month Evaluation of UPS Diesel Hybrid-Electric Delivery Vans," NREL/TP-5400- 53503, March 2012.

3. NREL Vehicle Drive Cycle Tool, User Guide. (C) 2009 Alliance for Sustainable Energy, LLC. All Rights Reserved.

4. Duran, A. and Earleywine, M., "GPS Data Filtration Method for Drive Cycle Analysis Applications," SAE Technical Paper 2012-01-0743, 2012, doi: 10.4271/2012-01-0743.

5. O'Keefe, M., Simpson, A., Kelly, K., and Pedersen, D., "Duty Cycle Characterization and Evaluation Towards Heavy Hybrid Vehicle Applications," SAE Technical Paper 2007-01-0302, 2007, doi:10.4271/2007-01-0302.

6. Taylor, J.R., An Introduction to Error Analysis. 2nd edition. Sausalito, California: University Science Books, 1997. pp 166-168.

\section{CONTACT INFORMATION}

michael.lammert@,nrel.gov

1617 Cole Blvd.

Golden, CO 80401

(303) 275-4067

adam.duran@nrel.gov

1617 Cole Blvd.

Golden, CO 80401

(303) 275-4586

petr.sindler@nrel.gov

1617 Cole Blvd.

Golden, CO 80401

(303) 275-3142

kevin.walkowicz@nrel.gov

1617 Cole Blvd.

Golden, CO 80401

(303) 275-4492

\section{ACKNOWLEDGMENTS}

This work was supported by the U.S. Department of Energy (DOE) Advanced Vehicle Testing Activity and would not have been possible without the generous donation of time and vehicles from the United Parcel Service of America, Inc. The authors wish to thank Lee Slezak at DOE, and Mike Britt, James Francis, Andy Grzelak, Bill Brentar and Robert Hall at UPS for their support.

\section{DEFINITIONS/ABBREVIATIONS}

CAN - controller area network

DPF - diesel particulate filter

DRIVE - Drive-Cycle Rapid Investigation, Visualization, and Evaluation

ECM - electronic control module

GPS - Global Positioning System

HHDDT - Heavy Heavy-Duty Diesel Truck

HTUF - Hybrid Truck Users Forum

NREL - National Renewable Energy Laboratory

NYC Comp - New York City Comp

ReFUEL - Renewable Fuels and Lubricants

UPS - United Parcel Service 


\section{$\underline{\text { APPENDIX }}$}

Table A1. J1939 Data Logging Channel List.

\begin{tabular}{|l|}
\hline J1939 Channel Name \\
\hline AccelPedalPos1 \\
\hline EngTorqueMode \\
\hline DriversDemandEngPercentTorque \\
\hline ActualEngPercentTorque \\
\hline EngSpeed \\
\hline FanSpeed \\
\hline EngTotalIdleFuelUsed \\
\hline EngTotalIdleHours \\
\hline EngTripFuel \\
\hline EngTotalFuelUsed \\
\hline EngCoolantTemp \\
\hline ParkingBrakeSwitch \\
\hline WheelBasedVehicleSpeed \\
\hline EngFuelRate \\
\hline EngInstantaneousFuelEconomy \\
\hline EngAverageFuelEconomy \\
\hline
\end{tabular}

Table A2. Monthly Vehicle Fuel Economy Results from UPS Records (raw with statistically removed months in gray and remaining months from one driver removed in darker gray).

\begin{tabular}{|c|c|c|c|c|c|c|c|c|c|c|c|c|c|c|c|c|c|c|}
\hline $\begin{array}{l}\text { Van } \\
\text { Num } \\
\end{array}$ & $\begin{array}{l}\text { July } \\
2010 \\
\end{array}$ & $\begin{array}{l}\text { Aug } \\
2010 \\
\end{array}$ & $\begin{array}{l}\text { Sept } \\
2010 \\
\end{array}$ & $\begin{array}{l}\text { Oct } \\
2010 \\
\end{array}$ & $\begin{array}{l}\text { Nov } \\
2010 \\
\end{array}$ & $\begin{array}{l}\text { Dec } \\
2010 \\
\end{array}$ & $\begin{array}{l}\text { Jan } \\
2011 \\
\end{array}$ & $\begin{array}{l}\text { Feb } \\
2011 \\
\end{array}$ & $\begin{array}{l}\text { Mar } \\
2011 \\
\end{array}$ & $\begin{array}{l}\text { Apr } \\
2011 \\
\end{array}$ & $\begin{array}{l}\text { May } \\
2011 \\
\end{array}$ & $\begin{array}{l}\text { June } \\
2011 \\
\end{array}$ & $\begin{array}{l}\text { July } \\
2011 \\
\end{array}$ & $\begin{array}{l}\text { Aug } \\
2011 \\
\end{array}$ & $\begin{array}{l}\text { Sept } \\
2011 \\
\end{array}$ & $\begin{array}{l}\text { Oct } \\
2011 \\
\end{array}$ & $\begin{array}{l}\text { Nov } \\
2011 \\
\end{array}$ & $\begin{array}{l}\text { Dec } \\
2011 \\
\end{array}$ \\
\hline 149765 & 8.85 & 8.91 & 9.01 & 8.95 & 8.68 & 9.87 & 8.68 & 8.96 & 9.13 & 7.85 & 8.87 & 9.56 & 7.64 & 9.35 & 6.75 & 8.26 & 8.20 & 9.30 \\
\hline 149772 & 11.82 & 10.25 & 16.06 & 29.30 & 9.84 & 10.50 & 7.67 & 9.76 & 11.49 & 9.31 & 7.98 & 8.34 & 7.25 & 7.15 & 7.18 & 7.73 & 6.96 & 7.14 \\
\hline 149777 & 7.77 & 8.49 & 8.78 & 7.98 & 9.50 & 7.95 & 9.05 & 8.55 & 7.41 & 8.08 & 7.89 & 8.12 & 6.65 & 7.02 & 6.46 & 7.22 & 5.54 & 6.35 \\
\hline 149779 & 9.06 & 13.41 & 8.00 & 8.52 & 10.13 & 9.24 & 13.06 & 12.33 & 12.05 & 31.18 & 7.75 & 8.52 & 8.51 & 7.32 & 8.69 & 7.75 & 8.55 & 7.33 \\
\hline 149780 & 10.78 & 12.74 & 9.74 & 11.92 & 7.80 & 7.87 & 7.59 & 9.28 & 10.43 & 8.53 & 10.83 & 9.74 & 11.11 & 7.39 & 9.63 & 8.28 & 8.15 & 8.88 \\
\hline 149783 & 8.23 & 8.91 & 9.49 & 11.61 & 10.79 & 9.22 & 7.62 & 7.48 & 8.96 & 9.10 & 12.44 & 7.75 & 27.57 & 14.39 & 9.25 & 9.89 & 27.68 & 6.68 \\
\hline 149784 & 8.63 & 8.98 & 7.16 & 8.40 & 8.43 & 8.98 & 7.50 & 9.40 & 8.52 & 11.90 & 13.01 & 10.53 & 7.92 & 10.51 & 20.16 & 15.02 & 21.38 & 10.45 \\
\hline 149831 & 11.31 & 9.40 & 8.61 & 9.51 & 8.62 & 7.74 & 8.47 & 7.41 & 9.31 & 8.13 & 7.89 & 9.40 & 8.59 & 9.69 & 8.01 & 7.62 & 7.33 & 9.94 \\
\hline 149832 & 8.07 & 8.01 & 10.26 & 11.11 & 9.54 & 7.38 & 9.81 & 14.23 & 8.89 & 11.01 & 7.87 & 8.82 & 9.14 & 35.52 & 25.46 & 53.75 & 54.25 & 23.45 \\
\hline 149833 & 9.50 & 9.46 & 10.17 & 9.62 & 9.41 & 8.64 & 9.96 & 8.84 & 9.42 & 10.09 & 9.31 & 10.46 & 9.80 & 10.06 & 8.38 & 7.92 & 9.84 & 7.13 \\
\hline 149871 & 9.73 & 11.22 & 10.15 & 9.40 & 8.49 & 8.94 & 9.94 & 10.69 & 9.42 & 10.86 & 6.79 & 8.31 & 8.08 & 7.24 & 7.48 & 7.86 & 6.69 & 6.55 \\
\hline 144561 & 10.00 & \#DIV/0! & 8.60 & 10.18 & 10.00 & 7.10 & 7.62 & 8.59 & 7.84 & 11.49 & 8.63 & 20.60 & 8.75 & 9.22 & 9.82 & 8.95 & 11.05 & 8.41 \\
\hline 144564 & 12.07 & 11.20 & 7.57 & 9.40 & 9.61 & 7.79 & 8.29 & 8.16 & 11.30 & 8.70 & 11.06 & 12.09 & 11.50 & 13.08 & 14.44 & 12.16 & 12.85 & 13.02 \\
\hline 144590 & 10.29 & 10.01 & 27.30 & 10.27 & 12.04 & 10.23 & 10.06 & 10.15 & 10.35 & 11.34 & 12.25 & 13.24 & 10.81 & 12.67 & 12.09 & 10.44 & 10.39 & 10.33 \\
\hline 144594 & 26.48 & 17.08 & 21.89 & 24.52 & \#DIV/0! & \#DIV/0! & \#DIV/0! & 23.25 & 28.42 & \#DIV/0! & 18.11 & \#DIV/0! & 18.10 & 22.47 & 10.54 & 9.76 & 11.01 & 9.30 \\
\hline 144595 & 11.92 & 7.53 & 13.73 & 13.22 & 7.89 & 8.45 & 8.09 & 8.71 & 8.38 & 12.00 & 14.84 & 13.78 & 36.82 & 28.91 & 10.93 & 19.98 & 23.02 & 12.74 \\
\hline 144596 & 9.27 & 10.20 & 14.98 & 9.08 & 13.88 & 7.90 & 8.28 & 8.52 & 7.52 & 10.30 & 23.82 & 11.17 & 12.07 & 8.42 & 10.55 & 10.86 & 8.92 & 10.35 \\
\hline 144597 & 21.54 & 21.00 & 19.64 & 11.40 & 18.20 & 7.11 & 6.76 & 9.22 & 8.51 & 7.99 & 15.13 & 9.43 & 10.10 & 8.83 & 10.36 & 8.45 & 8.06 & 7.74 \\
\hline 144598 & 13.85 & 8.80 & 12.69 & 7.55 & 8.34 & 7.66 & 11.39 & 20.86 & 9.28 & 12.09 & 10.06 & 25.57 & 9.08 & 11.76 & 14.39 & 12.21 & 10.47 & 9.29 \\
\hline 144712 & 13.56 & 8.04 & 15.98 & 55.64 & 14.37 & 7.66 & 9.04 & 7.83 & 9.50 & 12.51 & 9.22 & 9.46 & 11.20 & 11.46 & 10.65 & 9.61 & 10.97 & 9.25 \\
\hline 144719 & 10.97 & 10.08 & 12.07 & 14.11 & 8.06 & 7.94 & 6.92 & 8.98 & 8.64 & 9.61 & 9.34 & 9.88 & 10.53 & 10.08 & 8.32 & 9.86 & 11.59 & 9.13 \\
\hline 144736 & 10.62 & 11.36 & 11.93 & 12.71 & 11.83 & 11.16 & 13.68 & 18.61 & \#DIN/01 & 46.00 & 29.85 & 36.11 & 8.48 & 11.02 & 12.08 & 30.64 & 13.96 & 9.28 \\
\hline
\end{tabular}

The Engineering Meetings Board has approved this paper for publication. It has successfully completed SAE's peer review process under the supervision of the session organizer. This process requires a minimum of three (3) reviews by industry experts. ISSN 0148-7191
Positions and opinions advanced in this paper are those of the author(s) and not necessarily those of SAE. The author is solely responsible for the content of the paper.

SAE Customer Service:

Tel: 877-606-7323 (inside USA and Canada)

Tel: 724-776-4970 (outside USA)

Fax: 724-776-0790

Email: CustomerService@sae.org

SAE Web Address: http://www.sae.org

Printed in USA 